A N N A L E S Annales de Bretagne et des Pays de l'Ouest

Anjou. Maine. Poitou-Charente. Touraine

109-1 | 2002

Varia

\title{
Les « homes de foy » vendômois de 1355 à 1419 Un monde sans bouleversements
}

\section{Christophe Marion}

\section{(2) OpenEdition}

\section{Journals}

Édition électronique

URL : http://journals.openedition.org/abpo/1625

DOI : $10.4000 /$ abpo. 1625

ISBN : 978-2-7535-1485-0

ISSN : 2108-6443

Éditeur

Presses universitaires de Rennes

Édition imprimée

Date de publication : 20 mars 2002

Pagination : 7-30

ISBN : 978-2-86847-708-8

ISSN : 0399-0826

\section{Référence électronique}

Christophe Marion, «Les « homes de foy » vendômois de 1355 à 1419 Un monde sans

bouleversements ", Annales de Bretagne et des Pays de l'Ouest [En ligne], 109-1 | 2002, mis en ligne le

20 mars 2004, consulté le 01 mai 2019. URL : http://journals.openedition.org/abpo/1625 ; DOI :

$10.4000 / a b p o .1625$ 


\title{
Les " homes de foy " vendômois de 1355 à 1419 Un monde sans bouleversements
}

\author{
Christophe MARION \\ Doctorant, Laboratoire de médiévistique occidentale de Paris, Université Paris 1 \\ enseignant au lycée Ronsard de Vendôme
}

Le bas Moyen Âge passe traditionnellement pour avoir connu de grands bouleversements économiques, politiques mais surtout sociaux ${ }^{1}$. Le Vendômois ne semble pas avoir échappé à la règle : l'étude par Dominique Barthélemy d'un registre recensant les 81 fiefs relevant de la châtellenie de Vendôme ${ }^{2}$ lui avait permis d'appréhender le monde des "homes de foy" vers 1355 et d'insister sur le naufrage de plusieurs lignées chevaleresques ainsi que sur le triomphe de quelques roturiers en voie d'anoblissement ${ }^{3}$. Toutefois, si le Livre des fiefs permet de dresser un tableau de la société féodale au milieu du XIV e siècle, il permet également d'en suivre les évolutions, grâce à la rédaction d'une nouvelle liste 70 ans plus tard : " C'est la table des noms des hommes de foy de la chastellenie de Vendosme cy après nommés factes après Pasques l'an 400 et XIX. " Ainsi donc notre document permet, grâce à cet additif, d'établir un nouvel état en 1419 et de poser un regard différent sur une problématique trop longtemps prisonnière de la " crise nobiliaire " et du " triomphe bourgeois".

L'intérêt que suscite le Livre des fiefs ne doit pas occulter les limites de la source. Tout d'abord, il s'intéresse uniquement à la châtellenie de Vendôme, plus particulièrement à la petite Beauce et au val de Loir, c'està-dire à une partie réduite du comté ${ }^{4}$. De plus, il a été composé à partir d'enquêtes, d'aveux et de documents de dates diverses ${ }^{5}$ : il n'indique donc pro-

1. Voir éléments de bibliographie à la fin de l'article.

2. BARTHELEMY, Dominique, La société dans le comté de Vendôme de l'an mil au XIV siècle, Paris, Fayard, 1993, p. 26, 82 : "Ce sont les fiés rerefiés de la chastelerie de Vendosme appartenans a monseignour le comte de Vendosme, et qui luy sont tenus et advoez tant nuement come par moyen, a cause de son chastel et chastellie de Vendosme ", Archives nationales (abrégé : AN), P 976.

3. BARTHELEMY, Dominique, La société dans le comté de Vendôme..., op. cit., p. 252 et suiv.

4. Ibidem, p. 212.

5. «Selon ce que ledit jacquet les a trouvés et verefiés par enquestes par monstrées et informations faittes o les anciens et savanz du pais et par aucuns advous anciens, avec les quelx il en a fait concordance ", AN, P 976. 
bablement pas la situation exactement en $1355^{6}$. En outre, il est incomplet et probablement inachevé : certains fiefs ont été oubliés par le compilateur. C'est le cas de la Rocheturpin ${ }^{7}$ mais également de la seigneurie de Villeluisant. En 1343, Jehan Moreau avouait aux comtes de Vendôme et de Blois son habergement de Villeluisant en Selommes ${ }^{8}$. Or, aucune trace ne figure dans le Livre. Enfin, Il nous interdit de suivre les changements qui affectèrent le contenu des fiefs même si nous savons par ailleurs qu'ils furent nombreux (la table de 1419, en ne décrivant pas le " domaine ", les $\left.\operatorname{cache}^{9}\right)$. La consultation des registres ${ }^{10}$ contenant les aveux et dénombrements vendômois nous permettra de compléter ce travail.

Si notre document permet de suivre les destinées des fiefs, il nous révèle également les progrès de l'administration comtale. En effet, alors que les Bourbon-Vendôme menaient une politique à l'échelle du royaume et résidaient de moins en moins souvent sur leur terre patrimoniale; les baillis, receveurs, procureurs et autres " gens du conseil " prirent en main la direction du comté, veillèrent au respect des droits du maître et reçurent avec "grante sollanité comme accoutumée " les "serments de féaux" lors des assises de la châtellenie. La fidélité et les compétences de ces " serviteurs " permirent à " l'État local " de traverser plusieurs périodes de faiblesse ou de crise ${ }^{11}$.

Le Vendômois ne semble pas avoir connu de bouleversements profonds entre 1355 et 1419 (annexe). En effet, dans presque un tiers des cas, le fief resta aux mains de familles portant le même patronyme. De plus, nous croyons pouvoir dire qu'entre les feudataires de 1355 et ceux de 1419 existaient des liens familiaux divers dans plus de $55 \%$ des cas environ ${ }^{12}$. Enfin, si notre corpus ne nous a pas permis de démêler l'histoire de chaque " domaine ", il semble néanmoins indiquer la part relativement faible de la transmission par achats ou dons (nous mettons ensemble ces deux modes

6. La même remarque s'applique également pour la table de 1419. En effet, Hue de Bellay y est très souvent cité comme feudataire " à cause de sa femme, fille Guillaume Montigny " alors qu'il fut tué à la bataille d'Azincourt : Livre des fiefs $\mathrm{N}^{\circ} 11,56,4$. SAINTVENANT, Raoul Barré de, Dictionnaire topographique, historique, biographique, généalogique et héraldique du Vendômois, 4 vol., Blois, 1912-1917, II, page 239.

7. " On remarquera tout de même qu'il aurait pu décrire la seigneurie de la Rocheturpin, tout à fait extérieure à la châtellenie de Vendôme mais vouée à mouvoir toujours de ce château ", BARTHELEMY, Dominique, La société dans le comté de Vendôme... op. cit., p. 839.

8. AN, Q 1439, 1343.

9. En 1355, Jehan Buglé avouait la Ratellerie et Villetuboeuf [Villiersfaux]. Or un aveu et dénombrement plus tardif de la Maison-Dieu nous apprend que ces deux métairies étaient séparées après 1364 et tenues par deux feudataires différents, Livre des fiefs n ${ }^{\circ} 29$, Bibliothèque municipale de Vendôme, ms. 285, 1364.

10. Série $P$ des AN.

11. Le registre de 1355 fut rédigé après la mort de Bouchard VI et la table de 1419 alors que Louis de Bourbon était prisonnier en Angleterre depuis quatre années.

12. Ce qui signifie que $64 \%$ environ des fiefs étaient, en 1419 , aux mains de seigneurs liés familialement aux feudataires de 1355 . Ces chiffres sont très probablement des minima. 
de dévolution tant ils semblent parfois difficiles à séparer ${ }^{13}$ ). Même si plusieurs incertitudes demeurent quant à ces chiffres, ils permettent de dresser un tableau où les permanences l'emportent sur les changements. S'il y eut bien une revolutio dans le Vendômois bas-médiéval entre 1355 et 1419, il faut entendre le terme dans son sens latin.

\section{Un dynamisme comtal certain}

Le sentiment de continuité qui se dégage de cette étude ne doit pas masquer quelques nouveautés, au premier rang desquelles figure le renforcement de l'autorité comtale. En effet, le Livre des fiefs met en évidence l'active politique d'achats des comtes de Vendôme, confirmée par la découverte de quelques actes épars. En 1368 (c'est-à-dire trois ans avant l'avènement des Bourbon), Alix de Bretagne dressait la liste des « biens acquis dans la chastellenie de Vendosme durant son mariage avec Bouchard jadis comte de Vendosme", achats " communs entre elle et sondit espoux " (Bouchard VI, mort en 1354) ${ }^{14}$. S'il n'est pas question de détailler le document, nous pouvons tout de même constater que les achats de "terres" (métairies, aîtres, parcelles) furent assez rares : la métairie de la Touche (Villemardy) et " deux mouées de terre près la métairie de Crévecé [Sainte-Gemmes] à la Touche " (probablement pour agrandir l'acquisition précédente). Le domaine foncier du comte demeurait, somme toute, assez limité ${ }^{15}$. Parmi les achats de rentes, celles qui grevaient les services affermés du comté furent privilégiées ${ }^{16}$. C'est probablement dans ce contexte d'affirmation de l'autorité comtale qu'il faudrait placer l'achat par Bouchard ou sa veuve de la rente assise sur la voirie de la châtellenie ${ }^{17}$.

Avec l'arrivée des Bourbon en 1371, cette politique d'achat prit une nouvelle dimension : probablement alimentée par « les profits de guerre et de

13. Si Guillaume de Poncé avait donné " par pure aumône " la seigneurie de Courtiras à l'Hôtel-Dieu, force est de constater qu'il avait déjà sérieusement entamé son patrimoine. En 1351, il avait vendu la métairie de Maudétour [Naveil] à Gervais Malon. Ce dernier avait également acquis plusieurs rentes assises sur cette terre (62 livres et 6 muids de grains : la donation précise que des arrérages étaient dus), Bibli. mun. de Vendôme, ms. 285 .

14. AN, Q 1443, 1368.

15. "Le domaine foncier du comte n'est pas très important en châtellenie de Vendôme : on y trouve que deux fermes et quatre métairies ", BARTHELEMY, Dominique, La société dans le comté de Vendôme..., op. cit., p. 891.

16. 26 sous 4 deniers acquis de Jehan du Plessis sur les fours de Vendôme; 10 sous acquis de Guillaume de Souday sur la Boucherie de Vendôme; 11 livres, 11 sous et 3 deniers acquis du seigneur de Sully sur les exécutions de Vendôme; 40 livres acquis du même sur la criée de Vendôme; 8 livres acquis de Agaithe des Hayes sur la coutume des chanvres et lins. En 1332, la même Agaithe des Haies vendait au comte ses droits sur la crierie de Vendôme, qu'elle tenait en fief (AN, Q 1504, 1332). Les Comptes de 1354 nous révèlent que ces services étaient affermés par des Vendômois (que l'on retrouva d'ailleurs parfois dans la bourgeoisie du siècle suivant) mais grevés de rentes tenues par des membres de l'aristocratie locale. Ce paradoxe devra être étudié (AN, P 973, 1354).

17. Livre des fiefs $n^{\circ} 9$. 
cour " de Louis ${ }^{\text {er } 18}$, elle utilisa tous les ressorts proposés par la " société féodale ". En 1409, un bourgeois de Château-Gonthier, Jehan l'Arsonneur, avait acheté à la veuve de messire Fouquet du Merle la terre de "Boys Breton et du Monceau avec leurs appartenances tant en fiefs, domaines, justice et seigneurie en la chastellenie de Vendosme, et avec ce la terre d'Auton avec appartenances tant en fiefs et domaines ${ }^{19}$ ". Le comte décida de conserver ces terres "par retrait de fie " et paya la somme de 900 livres à l'Arsonneur, annulant ainsi la transaction de 1409. Le retrait "par prochaineté de lignage " avait les faveurs des Vendôme, dès avant 1371 : c'est ainsi que Bouchard VI s'était emparé de rentes assises par Pierre de Vendôme sur la terre du Boulay en Authon (10 muids de froment en tout ${ }^{20}$. Quelques années plus tard, ce dernier abandonnait le fief à son lointain cousin ${ }^{21}$. De manière générale, il est probable que les comtes profitèrent des difficultés passagères d'une partie de l'aristocratie locale. Ce fut le cas avec la vente par le bâtard Regnault de Graçay de ses " chastel et chastellenie de Savigny $^{22}$ " contre une rente annuelle de 100 livres et la promesse de laisser son père Regnault jouir des revenus de la seigneurie sa vie durant ${ }^{23}$. Si nous ne connaissons pas ces revenus ${ }^{24}$, nous pouvons estimer l'importance de l'achat par son impressionnante mouvance (16 fiefs sans compter les arrièrefiefs) et sa haute justice. Le comte de Vendôme, comme le duc de Berry, profita de la liquidation du patrimoine familial des Graçay ${ }^{25}$. Les exemples de Mondoubleau et du fief d'Aubemare (Couture) mettent également en valeur l'opportunisme des Bourbon, prompts à profiter des difficultés passagères ou des changements de politique patrimoniale des chevaliers vendômois ${ }^{26}$.

18. Il fut le second Bourbon-Vendôme. Bertrand Schnerb a bien montré que la fréquentation des armes joua un rôle essentiel dans la promotion du lignage des Bournonville, SCHNERB, Bertrand, Enguerrand de Bournonville et les siens. Un lignage noble du Boulonnais aux $X I V^{e}-X V^{e}$ siècles, Collection Cultures et civilisations médiévales 14, Presses de l'Université de Paris-Sorbonne, Paris, 1997.

19. Livre des fiefs $n^{\circ} 51$.

20. Il avait lui aussi acheté une rente de 7 autres muids de froment à Pierre de Vendôme, son lointain cousin.

21. AN, Q 1429, 1347.

22. Savigny appartenait était un ancien domaine des Preuilly. Il avait été donné en parage à un frère cadet du comte de Vendôme au XIII ${ }^{\mathrm{e}}$ siècle et était passé aux mains des Graçay de Berry au début du XIV siècle, BARTHELEMY, Dominique, La société dans le comté de Vendôme... op. cit., p. 827.

23. AN, Q 1437, 1373.

24. Quelques années plus tard, Louis de Bourbon estimait les revenus annuels de la châtellenie à 220 livres (après en avoir retiré de la seigneurie la haute justice, la garenne de chasse, le four à ban...), AN, Q 1437, 1413.

25. Regnault de Graçay vendit sa baronnie de Graçay au duc de Berry en 1371, LA Chenaye des Bois, François-Alexandre Aubert de, BADIER, Jacques, Dictionnaire de la noblesse contenant les généalogies, l'histoire et la chronologie des familles nobles de France, 19 vol., Paris, 1863-1867.

26. La baronnie de Mondoubleau fut vendue en 1406 par le comte de Dammartin (SAINTVenant, Raoul Barré de, Dictionnaire..., op. cit., II, p. 408). En 1408, les seigneurs de Ranay (Marquet, Jehan et Margueritte de Lavardin) vendaient à Catherine de Vendôme (mère de Louis de Bourbon) le fief d'Aubemare (Couture), contenant 24 sous de cens, deux 
Deux constatations s'imposent : d'une part, ces achats furent souvent tournés vers les marches du comté. Ce fut le cas pour Authon, Mondoubleau, Savigny, Boisbreton et Beaumat. Les comtes renforçaient ainsi leur présence dans ces régions éloignées de Vendôme, parfois disputées par de puissants voisins. D'autre part, ils soustrayèrent ces " nouveaux acquests " du domaine et les redonnèrent en fief à des alliés du parti orléanais auquel se rattachait Louis $\mathrm{I}^{\mathrm{er}} 27$, mais également à des fils, bâtards ou puînés. En 1413, Jehan des Croix se voyait octroyer le " chastel et chastellerie de Savigny avec appartenances tant maisons, terres, vignes, bois, haies... à tenir, exploiter ledit chastel et chastellerie dudit Jehan et de ses héritiers males descendans de sa chaire en loial mariaige et non aultrement ». Si, à défaut de descendance masculine, le château passait entre les mains d'une femme, Louis $I^{\mathrm{er}}$ pourrait le reprendre, moyennant le paiement de 2500 livres. Cette donation était faite " par pure aumône, par remerciement des services faicts par le père de Jehan à ses prédécesseurs et par Jehan pour avoir poursui et pourchacé la délivrance du comte et que ledict Jehan le servira de mieux en mieux le temps advenir ${ }^{28}$ ". Nous avons cherché à savoir qui était cet écuyer qui devint, avec quelques restrictions ${ }^{29}$, seigneur de Savigny. Dans un premier temps, nous avions pensé qu'il s'agissait du seigneur de la Croix en Nivernais (cette localisation géographique nous permettait également de le lier avec les Graçay) ${ }^{30}$. Toutefois, nous pensons plus sûrement qu'il s'agissait de Jehan de Castries. D'une part son père avait déjà été désigné comme trésorier des États de Languedoc pour recouvrer par le passé la rançon de Jehan II le Bon dans la baronnie de Montpellier ${ }^{31}$. D'autre part, les Chroniques de France signalent, dans la région, les exploits militaires du baron de Castries, vainqueur des Anglais à Baugé (Anjou) vers 142132. Enfin, Raoul de Saint-Venant lui consacre une notice (sans véritablement l'identifier d'ailleurs) qui éclaire bien ses relations privilégiées avec le comte de Vendôme ${ }^{33}$. Quant au "sire de

arpents de pré et 14 sétrées de terre (AN, Q 1428, 1408). En fait, ils se débarrassaient ainsi d'un fief sur lequel était assis un nombre impressionnant de rentes, dont certaines d'ailleurs avaient été acquises par Jehan VII. En 1387, Jehan Poinvillain vendait au comte une rente assise sur la terre d'Aubemare, acquise de Monsieur Hue d'Aubemare en 1367 (AN, Q 1504, 1387, 1367). En 1346, Jehan et Henry d'Aubemare vendaient aux chanoines une rente en froment (15 setiers) sur " tous leurs biens ", Arch. dép. du Loir-et-Cher, G 2576, 1346.

27. Ce choix politique lui coûta plus d'une fois sa liberté : en 1407, il était fait prisonnier par les Bourguignons et en 1412 par son propre frère, Jacques, comte de la Marche. 28. AN, Q 1437, 1413.

29. Le comte se réservait les droits de péage, la garenne de chasse, la forêt, le four à ban, la dîme et la haute justice. En outre, si la seigneurie passait entre les mains d'une femme, Louis de Bourbon pourrait le reprendre.

30. LA Chenaye Des BoIs, Aubert François-Alexandre de, op. cit.

31. Duc de CASTRIES, Papiers de famille, France-Empire, Paris, 1977, p. 23.

32. Ibidem, p. 24.

33. Jehan de Croix avait été capturé avec le comte à Azincourt : libéré dès 1418, il servit le dauphin comme conseiller, gouverneur de Châteaurenault puis de Vendôme en 1423. À cette occasion, il enleva Marie, sœur du comte Louis, afin de l'épouser, encourant par 
Courcelles ", seigneur de Boisbreton en $1419^{34}$, nous pensons qu'il s'agit du chanoine $^{35}$ Raoul de Refuge ${ }^{36}$, frère de Jehan Refuge, général des Aides et conseiller du duc d'Orléans (à ces titres, il fut probablement un acteur important de la libération de Bourbon $)^{37}$. D'une manière générale, les liens entre la famille d'Orléans et notre région furent de plus en plus nombreux à partir de 1395, date à laquelle Louis d'Orléans devint seigneur de Fréteval $^{38}$. Si nous hésitons à dire que Louis ${ }^{\text {er }}$ participa au renouvellement de la noblesse locale (Boisbreton et Savigny sont, de ce point de vue, des échecs : les Croix et Reffuge ne s'implantèrent pas), nous devrons toujours garder à l'esprit, en constatant l'apparition d'un lignage exogène, l'éventualité d'un lien (militaire par exemple) avec les Bourbon-Vendôme. Enfin, les comtes utilisèrent ces terres récemment acquises afin de pourvoir leurs puînés (ce fut le cas pour Savigny ${ }^{39}$ et Schy ${ }^{40}$ ) ou leurs bâtards (Bonnevau en Savigny) ${ }^{41}$.

Le dynamisme comtal profita également à ses serviteurs. Guillot le Fèvre " demourrant à Vendôme " possédait un beau fief à Villemardy (comprenant des terres, des droits, la basse justice) $)^{42}$. Si le terme de " demourrant " éloigne les Lefèvre de la bourgeoisie pour les rapprocher des " gens de métiers ${ }^{43}$ ", nous pensons plutôt que leur notabilité rappelait celle des " gens du comte ": Guillot tenait à ferme de Bouchard VI le moulin à draps de Vendôme ${ }^{44}$. Quant à Robin Le Fèvre, il était " exécuteur des lettres obligatoires en la chastellenie de Vandosme ${ }^{45}$ ". En fait, il faut attendre le $\mathrm{XV}^{\mathrm{e}}$ siè-

là même la colère des comtes de Bourbon et peut-être même du roi, SAINT-VENANT, Raoul Barré de, Dictionnaire..., op. cit., I, p. 424.

34. Livre des fiefs $n^{\circ} 51$.

35. Un tel choix était intéressant pour Louis de Bourbon qui ne craignait pas, avec Raoul de Refuge, la transmission de Boisbreton à une hypothétique descendance masculine.

36. Il était seigneur de Courcelles (Lignières et Fréteval) depuis 1399, SAINT-VENANT, Raoul Barré de, Dictionnaire..., op. cit., I, p. 44.

37. La ChEnAYE des BoIs, op. cit.

38. Saint-Venant, Raoul Barré de, Dictionnaire..., op. cit., II, p. 99.

39. D’après Raoul de Saint-Venant, Jehan, troisième fils de Jehan VII reçut Savigny comme apanage : nous citons cette remarque avec beaucoup de prudence. En effet, Raoul de Saint-Venant pensait que Jehan de Bourbon avait été seigneur de Savigny à partir de 1403. Or, l'acte de 1413 ne va pas dans ce sens, SAINT-Venant, Raoul Barré de, Dictionnaire..., op. cit., III, p. 368; AN, Q 1437, 1413.

40. BARTHElemy, Dominique, La société dans le comté de Vendôme..., op. cit., p. 829.

41. Récemment acquis, il avait été donné par Bouchard V à son second fils Bouchard, puis retourna à Bouchard VI (son oncle n'ayant probablement pas eu de descendance). Au Xve siècle, Bonnevau fut donné à Jehan bâtard de Bourbon (fils de Louis de Bourbon et de Sybille de Boston). Puis, après retour à Jehan VIII, au fils naturel de ce dernier Jacques, bâtard de Bourbon, SAINT-VEnANT, Raoul Barré de, Dictionnaire..., op. cit., I, p. 167.

42. Livre des fiefs $n^{\circ} 16$.

43. En ce sens, BARTHELEMY, Dominique, La société dans le comté de Vendôme..., op. cit., p. 986. D'ailleurs, les aveux postérieurs nommaient Guillot Lefèvre " demourrant à Vandosme " (et non " de Vendôme "); par exemple : AN, P 623, 1405.

44. AN, P 973, 1354.

45. Arch. dép. du Loir-et-Cher, 21 H 104, 1355. 
cle pour connaître un peu mieux la famille. On rencontre en 1459 (seulement) le titre de bourgeois ${ }^{46}$ associé à Guillot, par ailleurs qualifié de conseiller en cours laïe ${ }^{47}$. Jehan Lefèvre fut maître et administrateur de la Maison Dieu, durant la première moitié du $\mathrm{Xv}^{\mathrm{e}}$ siècle $^{48}$. Hélye tenait une tannerie rue Chevrie et était procureur de la confrérie de Sainte Opportune ${ }^{49}$. Il faudrait donc insister sur les multiples activités de la famille, qui avait manifestement plusieurs cordes à son arc : bourgeoisie, service du comte, métiers, justice, carrières ecclésiastiques... Le service administratif n'était jamais exclusif ${ }^{50}$. Nous hésiterons donc à imputer au fonctionnaire seigneurial une réussite qui lui venait peut-être de la tannerie.

\section{" L'âge d'or " de la collégiale castrale}

Étudier le dynamisme des Bourbon-Vendôme, c'est également s'intéresser à celui de leur collégiale castrale, haut lieu de l'identité comtale. En effet, le Livre des fiefs nous laisse entrevoir la prospérité de ces chanoines, qui achetèrent ou se firent donner durant cette période de nombreux "domaines" (sous ce terme, notre document entend aussi bien des cens et rentes que des terres ou des métairies ${ }^{51}$. Dans deux cas, ces derniers étaient grevés d'une rente envers le chapitre ${ }^{52}$ ou d'autres établissements religieux ${ }^{53}$. L'endettement a, dans certains cas, pu favoriser le transport de propriété vers les établissements religieux.

La période allant de 1355 à 1419 fut un grand moment de l'histoire capitulaire. En effet, la prospérité de l'établissement fut alors à son apogée. Cet "âge d'or " doit être comparé avec le siècle suivant (entre 1440 et 1542) durant lequel le chapitre, davantage préoccupé de remettre en état la campagne vendômoise en pleine convalescence, acheta très peu de domaines :

46. Guillot Lefèvre, bourgeois demeurant à Vendôme (et non " de Vendôme ") prenait des prés à Lunay en 1459, Arch. dép. du Loir-et-Cher, G 275, 1459.

47. Arch. dép. du Loir-et-Cher, 53 H 11, 1461.

48. On le vit prêter hommage au comte pour les domaines de la Maison-Dieu en 1445, AN, P 604, 1445.

49. Arch. dép. du Loir-et-Cher, G 317, 1475.

50. Jacquet du Pont était voyer de Vendôme et rédacteur du Livre des Fiefs. Or, à la suite du décès d'André du Pont, ses biens étaient partagés entre messire Pierre du Pont, prêtre, et Jacquet, clerc. Ce dernier récupérait une maison rue Chevrie " avec la tannerie darrière ", Arch. dép. du Loir-et-Cher, G 238, 1339.

51. Livre des fiefs $\mathrm{n}^{\circ} 6$ (terres et revenus divers à Périgny), 12 (cens et rentes à Rocé, Vulletrun et Naveil), 23 (métairie de la Grassière à Villemardy), 29 (bois à Villiersfaux), 37 (terres et revenus divers à Marcilly), 41 (une corvée de charpentier à Vendôme), 44 (prés à Pezou), 50 (justice de 60 sous à Rocé).

52. Une rente de deux setiers de froment était assise sur les terres de Jehan Buglé (d'autres rentes étaient dues à des établissements religieux divers) : Livre des fiefs $n^{\circ} 29 ; 1 / 2$ muid de froment était assis sur les Bordes (Livre des fiefs $n^{\circ} 37$ ). La métairie de la Grassière devait une rente de 18 setiers de froment (Livre des fiefs $n^{\circ} 23$ ).

53. Nous sommes surpris de constater l'absence de trace d'un éventuel « crédit bourgeois ". Les lacunes du document nous empêchent très probablement d'apprécier toutes les charges qui grevaient les biens. 
Les achats capitulaires, 1348-1419 ${ }^{54}$

\begin{tabular}{|c|c|c|c|}
\hline Acte & Date & Description & Statut du vendeur \\
\hline $41 \mathrm{H} 66,1336$ & Avant 1366 & Métairie de Rochehaye (Villerable) & $\begin{array}{l}\text { Veuve bourgeois } \\
\text { de Vendôme }\end{array}$ \\
\hline G 294 & 1348 & 2 sétrées de terre (Saint-Rimay) & \\
\hline G 2576 & 1349 & Métairie de Villarceau (Selommes) & Chevalier \\
\hline G 2576 & 1365 & Métairie à Selommes & $\begin{array}{l}\text { Bourgeois } \\
\text { de Vendôme }\end{array}$ \\
\hline G 268 & 1367 & $\begin{array}{c}\text { Métairie de la Fortinière } \\
\text { (Gombergean) }\end{array}$ & $\begin{array}{c}\text { Écuyer, } \\
\text { seigneur de Noyers }\end{array}$ \\
\hline G 2566 & 1395 & Dîme de Coulommiers & Écuyer \\
\hline G 2577 & 1399 & Hôtel du Barillet (Vendôme) & \\
\hline G 2574,1400 & Vers 1400 & $\begin{array}{c}\text { La Béginière (Rocé), une métairie } \\
\text { à Périgny, une métairie } \\
\text { à Bixard (Renay) }\end{array}$ & $\begin{array}{l}\text { Bourgeois } \\
\text { de Vendôme }\end{array}$ \\
\hline G 2575 & 1404 & Dîme de Saint Firmin et Pezou & $\begin{array}{l}\text { Paroissien } \\
\text { de Vendôme }\end{array}$ \\
\hline G 308 & 1407 & 1,5 boisselée de terre (Villiersfaux) & Écuyer \\
\hline G 308 & 1408 & 2 sétrées de terre (Villiersfaux) & Paroissien de Nourray \\
\hline $\mathrm{LF} \mathrm{n}^{\circ} 6$ & $?$ & Terres et revenus divers à Périgny & Damoiselle \\
\hline $\mathrm{LF} \mathrm{n}^{\circ} 23$ & $?$ & $\begin{array}{l}\text { Métairie de la Grassière } \\
\text { (Villemardy) }\end{array}$ & Écuyer \\
\hline $\mathrm{LF} \mathrm{n}^{\circ} 50$ & Vers 1400 & Justice de 60 sous & $\begin{array}{l}\text { Bourgeois } \\
\text { de Vendôme }\end{array}$ \\
\hline $\mathrm{LF} \mathrm{n}^{\circ} 12$ & $?$ & Cens et rentes à Rocé, Villetrun... & Damoiselle \\
\hline
\end{tabular}

les acquisitions se concentrèrent alors dans la première moitié du XVI ${ }^{e}$ siècle $^{56}$ et ne concernèrent souvent que de minuscules parcelles (quelques boisselées) ou de très faibles cens ( 2 sous dans un cas, 5 deniers dans l'autre $)^{57}$. Seul le fief de la Poterne (Azé) trancha avec cette modestie, même si les deux-tiers furent vendus 272 livres seulement. En outre, l'aveu de 1355 rendu par les chanoines à Antoine de Bourbon révèle le triste état de cette petite seigneurie (à peine 30 hectares) ${ }^{58}$.

Les facteurs de cette réussite semblent avoir été nombreux, même si la disparition des registres capitulaires ou des comptes de receveurs nous oblige à émettre beaucoup d'hypothèses. L'appui de l'autorité comtale fut probablement essentiel. Au moment où d'autres chapitres urbains connaissaient de nombreuses difficultés ${ }^{59}$, le comte Louis portait en 1428 le nom-

54. Nous avons exclu les " domaines " qui ont pu être donnés (Livre des fiefs $n^{\circ} 41,29$, $44,37)$ ainsi que les achats de rentes.

55. Nous ne savons pas ici s'il s'agit d'une vente ou d'un don.

56. Guy Fourquin notait déjà que les substantiels accroissements dont avaient profité certains patrimoines religieux au cours de la guerre de Cent Ans ne s'étaient pas poursuivis ensuite : FouRQuIN, Guy, Les campagnes de la région parisienne à la fin du Moyen Âge, Paris, 1964.

57. Arch. dép. du Loir-et-Cher, G 2588, 1474; G 2574, 1535.

58. Arch. dép. du Loir-et-Cher, G 326, 1555.

59. En 1423, les chanoines du chapitre cathédrale de Limoges demandaient au pape la réduction des prébendes et canonicats de vingt à trente; le chapitre de Notre-Dame de 
bre de chanoines de douze à vingt par la création de huit hebdomadiers. Il souhaitait probablement ainsi asseoir son autorité sur une collégiale castrale fondée par une dynastie antérieure. " Nouveau fondateur ", il rattachait donc sa lignée, fraîchement installée à la tête du Vendômois, à un haut lieu de la mémoire comtale et par la même aux anciens seigneurs ${ }^{60}$. Les achats capitulaires démontrent finalement autant le dynamisme de l'autorité comtale que celui des chanoines. Ces derniers profitèrent également de l'afflux régulier de dons, venus principalement de la ville (et peut-être plus encore de la notabilité urbaine). Enfin, une gestion rigoureuse de leurs terres et une mise en place intelligente de " politiques de reconstruction " expliquent leur bonne santé financière ${ }^{61}$.

\section{Des laboureurs " par la petite porte "?}

La prospérité capitulaire profita également à quelques hommes qui, aidés par les circonstances, pénétrèrent " par la petite porte " dans le monde des feudataires. En effet, les chanoines étaient " gens d'Église " et ne " pouvoient tenir temporalités se elles ne sont amorties ${ }^{62}$ ". Le seigneur devait les autoriser à tenir leurs biens en main morte (cet amortissement prenait l'aspect d'un don ou d'une vente), à charge ensuite pour le chapitre de bailler un homme vivant et mourant (ou vicaire) à la mort duquel les devoirs seigneuriaux étaient payés. Toutefois, le seigneur pouvait également contraindre la collégiale à mettre " hors de ses mains " ses " acquests ". Dans ce cas ils pouvaient être arrentés à un chanoine ${ }^{63}$ ou à d'authentiques paysans. En 1355, la métairie de la Grassière était avouée par Gillet de Villeronce, à cause de sa femme, veuve d'un autre écuyer, Jehan de la Boce. Or, 70 ans plus tard, elle était passée entre les mains de Macé Roussineau. Une lecture trop rapide de l'acte pourrait nous faire croire à la " conquête " d'une métairie noble par un homme dont le nom sentait bien la roture. Une impression qui semble se confirmer par la suite : à partir de 1423, elle était avouée par les Chevrier, des notables urbains ${ }^{64}$. Toutefois, le fonds de Saint-Georges nous apprend que la collégiale avait baillé perpétuellement à Jehan Chevrier la Grassière " comme Macé Roussineau et André Cornet l'ont tenue ${ }^{65}$ ". Nous pensons qu'elle lui fut

Poitiers supprimait en 1389 la chèvecerie, en 1402 l'écolâtre, FAVREAU, Robert, La ville de Poitiers à la fin du Moyen Âge. Une capitale régionale, 2 vol., Poitiers, 1978.

60. Cette volonté fut marquée également par le choix des Bourbon-Vendôme de se faire enterrer dans l'enceinte de la collégiale, comme leurs prédécesseurs.

61. MARION, Christophe, La reconstruction des campagnes vendômoises à travers l'exemple des domaines de la collégiale Saint-Georges de Vendôme, Mémoire de Maîtrise, Université de Tours, 1995.

62. Arch. dép. du Loir-et-Cher, G 297, 1454.

63. Multiples exemples : Arch. dép. du Loir-et-Cher, G 232, 1442; G 238, 1491; G 250, 1447; G 316, 1520.

64. AN, P 621, 1423, 1434, 1430, 1484. En 1484, Michel Chevrier, fils de Jehan (feudataire de 1423), était qualifié de " bourgeois de Vendôme " (alors que son père ne l'était pas).

65. Arch. dép. du Loir-et-Cher, G 301, 1421. 
donnée ou vendue par Villeronce ${ }^{66}$, avant d'être arrentée à des laboureurs ${ }^{67}$ puis à des bourgeois de Vendôme (qui la sous-louèrent par la suite) ${ }^{68}$. Le bail à rente perpétuelle n'était pas une mauvaise opération pour les ecclésiastiques qui, en ces temps de "l'homme rare", pouvaient difficilement imposer la location à court terme (ou même à deux ou trois vies) ${ }^{69}$. Il permettait également à des paysans aisés de tenir une exploitation encore très proche d'une seigneurie ${ }^{70}$ et de devenir "home de foy" du comte. Macé Roussineau, dont on peut faire un laboureur de métairie ou un seigneur de la Grassière, devait même au comte un hommage lige et sept jours de garde au château ${ }^{71}$. Toutefois, la rente était si lourde qu'André Cornet ${ }^{72}$ (probable successeur de Roussineau) connut des difficultés à la régler. Dans le nouveau bail de 1421, Jehan Chevrier de Vendôme s'engageait à régler la " somme de 21 setiers de froment à la dicte mesure que ledit André Cornet devoit à Saint-Georges, arréages de rente de la dicte mestairie ${ }^{73}$ ". Mettre en valeur un tel ensemble nécessitait des " reins solides " : très vite, les laboureurs furent concurrencés par des notables urbains.

\section{Typologie des " conquêtes bourgeoises "}

Le dynamisme de ces derniers, volontiers qualifiés de " conquérants" a longtemps été au centre de tous les débats. Si l'exemple de la Grassière invite à se demander s'ils ne " conquirent " finalement pas davantage les positions paysannes que celles de la chevalerie, d'autres études récentes, en s'intéressant aux relations complexes qui unissaient roturiers et nobles, nuancent un certain nombre de conclusions quelque peu anciennes. En Vendômois, la période qui va de 1355 à 1419 connut assez peu de « conquêtes bourgeoises " c'est-à-dire de prises en main d'un fief, qui appartenait à un personnage titré en 1355 (dans le Livre ou dans notre corpus) par un

66. Cette opération eut lieu avant 1360 : en effet, à cette date, Macé Roussineau avouait déjà la métairie, AN, P 621, 1360.

67. Un Perrin Roussineau prenait à ferme des frères de la Maison-Dieu un aître à Villemardy, comportant des vignes, terres et arbres (Bibliothèque municipale de Vendôme, ms. 285, 1437). En 1354, Geoffroy et Agnès Roucineau, paroissiens de Villerable, prenaient deux sétrées de terre à Villerable pour eux et leur fils, Macé (Arch. dép. du Loir-et-Cher, G 301, 1354). D'ailleurs, ce dernier résidait à la Grassière en 1399 (AN, P 621, 1399), tout comme André Cornet d'ailleurs (Arch. dép. du Loir-et-Cher, G 301, 1419 et 1421).

68. Le comte de Vendôme avait peut-être obligé les chanoines à « mettre hors de leurs mains " cette métairie.

69. SCHNAPPER, B., "Les baux à vie du $\mathrm{X}^{\mathrm{e}} \mathrm{au} \mathrm{XVI}^{\mathrm{e}}$ siècle ", Revue historique du droit français et étranger, 1957, p. 347-375.

70. La métairie de la Touche-Chenard était composée de terres mais également de 16 sous de taille, 4 sous 6 deniers de cens, une oblie, des terrages et même une mouvance, Livre des fiefs $\mathrm{N}^{\circ} 17$.

71. Le service fut probablement commué en argent, AN, P 621, 1360.

72. Nous pensons qu'il succéda à Roussineau et fut, comme lui, laboureur (les deux résidaient à la Grassière).

73. Arch. dép. du Loir-et-Cher, G 301, 1421. 
" ignoble ${ }^{74}$ ». Certaines n'en furent d'ailleurs pas. Nous ne saurions dire avec Raoul de Saint-Venant ${ }^{75}$ et Dominique Barthélemy ${ }^{76}$ que le passage du fief de la Boissière des mains de demoiselle Jehanne de la Boissière à celles des Belon symbolise le naufrage de l'aristocratie vendômoise ${ }^{77}$. En fait, plusieurs indications nous permettent de contredire le " profil bourgeois " de ce dernier lignage. Tout d'abord, lorsqu'ils avouaient la Boissière au comte, les Belon portaient quasiment toujours l'armigérat ${ }^{78}$. En outre, leurs alliances furent toujours dirigées vers la noblesse ${ }^{79}$. Enfin, dès 1293, Harmé Belon, chevalier et seigneur de Lorges (en Beauce), vendait au comte de Vendôme 30 livres assises sur les rentes de Vendôme qu'il avait héritées de sa femme ${ }^{80}$. Le nouveau feudataire de la Boissière serait donc plus sûrement le cadet d'un lignage à la chevalerie ancienne et prestigieuse. Il est très difficile de placer un individu dans un " groupe social ${ }^{81}$ " dont les contours sont extrêmement variables, alors même que la découverte d'un nouvel acte, l'absence irrégulière d'un titre, peuvent brouiller ou au contraire conforter l'hypothèse du chercheur. Malgré toutes ces réserves,

74. « La conquête bourgeoise du sol a été, sauf en plaine de France, presque aussi peu sensible dans les censives que dans les fiefs ", FourQuin, Guy, Les campagnes..., op. cit., p. 225. Dans le Lyonnais, les citadins hésitaient également à investir à cause de l'insécurité : LoRcin, Marie-Thérèse, Les campagnes de la région lyonnaise aux XIVe et XVe siècles, Lyon, 1974.

75. En 1364, l'aveu de la Maison-Dieu spécifiait que « Dame Jehanne de la Brosse tient de Céans à Foy et hommage et un roucin de service les fiefs et arrière-fiefs qui s'ensuivent : Foy et hommage à elle due par Geuffroy de Belon pour sa métairie des Murats (Villeromain)" (Bibli. mun. de Vendôme, ms. 285, 1364). Or, quelques années plus tard, Geuffroy Belon vendait à Macé Copelet et Jehan Malon sa part de la dite métairie (Bibli. mun. de Vendôme, ms. 285, 1367). Il n'en fallut pas plus à Raoul de Saint-Venant qui fit des Belon de bourgeois de Blois, SaINT-Venant, Raoul Barré de, Dictionnaire ..., op. cit., II, p. 470. Il était probablement trompé par le fait que les Murats relevaient de la Dame du Quartier de Blois. Toutefois, dans le même temps, il notait la présence de Jehan Belon, capitaine du château de Vendôme en 1328, lieutenant de Jehan de Lisle et capitaine pour le roi en Poitou. En 1363, il était maréchal d'Amaury de Craon, lieutenant du roi en Anjou, Maine et Touraine, SaINT-Venant, Raoul Barré de, Dictionnaire..., op. cit., I, p. 109.

76. Dominique Barthélemy notait que Jehanne de la Boissière « finit par recueillir le tout et, avec son mari Jehan de Boisgarnier, par vendre les trois fiefs avant 1376 aux Belon (Villiers) et aux Malon (Villetrun), c'est-à-dire à des bourgeois de Vendôme ", BARTHELEMY, Dominique, La société dans le comté de Vendôme..., op. cit., p. 863 et 982.

77. Livre des fiefs $n^{\circ} 67$.

78. AN, P 601, 1397, 1415, 1440, 1484.

79. Jehanne Belonne était mariée avec Allard de Courbenton, chevalier (AN, P 609, 1405). Dominique Barthélemy nous apprend que Huet Belon était marié avec Jehanne Ranay en 1311, Barthelemy, Dominique, La société dans le comté de Vendôme..., op. cit., p. 862.

80. AN, Q 1443, 1293. On retrouve des Belon seigneurs de Lorges au XIII siècle. La terre passa par la suite aux Le Jay, puis aux Montgomery ('héritière Le Jay épousait en secondes noces Robert de Montgomery en 1481), MARQUENET, Guy, "Le château de Lorges ", dans : Fallot, Joëlle, (dir.), Patrimoine dans votre commune : Lorges, Blois, CDPA, 1994.

81. C'est-à-dire un rassemblement d'individus qui se définissent eux-mêmes comme membres du groupe et qui sont définis par les autres comme membres de ce groupe (ÉTIENNE, Jean, [dir.], Dictionnaire de sociologie, Paris, Hatier, 1997). Les sources dont disposent le médiéviste n'apportent souvent que des réponses indirectes et faussées. 
le Livre des fiefs nous a permis de retenir 9 fiefs symboles d'une " conquête bourgeoise " (11\% des dénombrements de 1355) ${ }^{82}$ : on peut donc difficilement parler de modification sociale de la répartition de la propriété en Vendômois. Deux classements ont rendu possible le regroupement des cas envisagés, en privilégiant soit la localisation géographique (il paraît important de séparer les " domaines " situés à Vendôme ou dans les campagnes périurbaines $^{83}$ et ceux sis en Beauce vendômoise ${ }^{84}$ ) soit la valeur des fiefs (elle peut être estimée indirectement par l'importance du " domaine "). La mise en relation de ces deux critères nous a permis de mettre à part les habergements de Maugué et de Faye ainsi que la " terre " de Villetrun.

\section{Quelques éléments de la " crise nobiliaire " : le morcellement des fiefs}

Ces " terres et habergements " méritent que l'on s'y intéresse pour deux raisons. D'une part, on y retrouve trois points communs intéressants : le passage de la chevalerie (ou de l'armigérat) à la roture, la localisation dans la Beauce vendômoise (une terre au profil nobiliaire marqué), un contenu riche (terres, habergements mais également justice et mouvance) ${ }^{85}$. D'autre part, leur étude pourrait aisément prendre place dans une histoire de « la crise nobiliaire " au sein du comté car tous les ingrédients symbolisant le naufrage chevaleresque s'y retrouvent : des pratiques successorales entraînant l'émiettement du patrimoine, la vente de seigneuries et les "mésalliances".

L'exemple de Villetrun met en évidence la réalité du partage des seigneuries mais nous permet également de nuancer le rôle de la coutume successorale comme élément explicatif des difficultés de la noblesse vendômoise. En 1355, le fief était divisé entre Macé et Jehanne de la Boissière. Le premier avait vendu sa part probablement à Jehan Copelet dont la fille, Agnès, avait épousé Gervais Malon ${ }^{86}$. Celui-ci avait commencé à travailler à l'agrandissement de son héritage ${ }^{87}$ : le second mari d'Agnès, Jehan

82. Livre des fiefs $n^{\circ} 15,20,25,28,33,50,57$ et 58 (Villetrun), 66, 68. Nous avons exclu l'achat par Jehan Pélisson sur Guillaume de Saint-Amand d'une maison à Vendôme et de six quartiers de pré à Pezou qui semble être une opération de bien peu d'envergure (Livre des fiefs $\mathrm{n}^{\circ} 60$ ). Nous aurions pu également exclure la métairie d'Anseys tant la noblesse des Ourseau, feudataires de 1355, sent encore beaucoup la roture urbaine (Livre des fiefs 25).

83. Poiriers en Saint-Ouen, Saint-Firmin, Naveil... Dominique Barthélemy a écrit avant nous que la campagne proche avait été le terrain de prédilection des premiers investissements ruraux des citadins, et ce, dès le XIII ${ }^{\mathrm{e}}$ siècle.

84. Huisseau, Maugué en la Chapelle-Anschéry, Villetrun, Faye.

85. Villetrun était le quatrième fief de la châtellenie selon Dominique Barthélemy avec 120 ha de domaine labourable, 9 arrière-fiefs, la justice de 60 sous, un moulin et quelques cens, Barthelemy, Dominique, La société dans le comté de Vendôme..., op. cit., p. 982.

86. Les Copelet, Malon et Beauvoir sont qualifiés de bourgeois dans le corpus vendômois.

87. En 1362, Gervais Malon échangeait avec l'Hôtel-Dieu des rentes contre «toutes dîmes, maisons, courtils, roches, vergers, cens, tailles, rentes, hommages qu'elle [MaisonDieu] a au fief de demoiselle Jehanne de la Boissière en la paroisse de Villetrun à Foy et hommage et 5 livres de service ", Bibli. mun. de Vendôme, ms. 285, 1362. 
Beauvoir l'aîné tenait donc une moitié de Villetrun et paracheva l'œuvre de son prédécesseur en acquérant la moitié du fief qui était échue à Jehanne. À la suite d'arrangements successoraux divers, Jehan Malon récupéra la quasi-totalité de Villetrun, comme héritier de son père (la part de Macé) et comme héritier de sa mère (la part de Jehanne). Jehan Beauvoir avait donc rassemblé le fief morcelé, travaillant en cela pour Jehan Malon qui récupéra une terre remembrée et plus forte qu'en 1355. L'étude de la Chape (Vendôme) appelle les mêmes remarques ${ }^{88}$ et prouve que la pénétration bourgeoise dans le monde des feudataires fut facilitée par la faiblesse (c'està-dire la division des fiefs). Robert Boutruche, déjà, avait insisté sur l'importance du droit successoral, comme élément explicatif de la crise seigneuriale ${ }^{89}$. En outre, les procès ruineux engagés par la noblesse à la suite de problèmes engendrés par les successions furent cause de déclin pour certaines familles ${ }^{90}$. Dominique Barthélemy notait également la multiplication des mentions visibles, surtout en 1355, de partages de seigneuries (c'était le cas notamment pour l'habergement de Villetrun) ${ }^{91}$. Utiliser le Livre

88. Dominique Barthélemy notait que l'ensemble formé par " les moulins de la Chappe dans Vendôme et la terre de Chanteloup, conservé intact de 1123 à 1311, était dissocié entre cette date et 1355 : Chanteloup même, à l'exception de sa justice était ravalé au rang d'arrière-fief ", BARTHELEMY, Dominique, La société dans le comté de Vendôme..., op. cit., p. 953. Chanteloup avait été acquis par Gervais Malon. En effet, un procès opposait sa veuve, Agnès, aux moines de la Trinité qui affirmaient être seigneurs d'une rente en froment assise sur " Chanteloup et sur les moullins de la Chappe appartenans d'ancienneté à la dicte terre de Chanteloup " (Arch. dép. du Loir-et-Cher, 21 H 211 , 1364). Agnès contesta leur demande en affirmant que son mari avait bien acquis Chanteloup mais que la rente était assise sur les moulins, dont elle n'était pas détentrice. Le domaine passa aux mains de Jehan de Beauvoir : il avouait " à cause de sa femme " à Jehanne la Freslonne sa terre de Chanteloup une belle seigneurie contenant un habergement, trois mouées de terre, moyenne justice (la haute étant tenue du comte), cens, rentes, terrages et corvées (AN, P $627 n^{\circ} 33$ ). Toutefois, Le Livre complète notre information en indiquant que les deux moulins de la Chape ainsi que les trois " grands méfais de justice " (c'est-à-dire la haute justice) en la terre de Chanteloup (Villerable) étaient passés aux mains des Malon en 1419 (Livre des fiefs $n^{\circ}$ 50). Ils furent très probablement acquis par Jehan de Beauvoir sur Berthelot du Pin : au moment du partage des biens de Jehan de Beauvoir, les Malon demandèrent la " moictié par indivis de tous les achapts qu'ils (Beauvoir et sa femme Agnès) firent en la terre de Chanteloup de feu Hardouin du Pin écuier " (E 192, 1394). Ainsi, alors que le fief avait été divisé, probablement entre deux frères (la Chappe appartenait à Berthelot du Pin; or le procès de 1364 mentionne que l'achat de Chanteloup avait été fait sur "Perrot seigneur de Chanteloup ", probablement Pierre du Pin), l'ensemble avait été reconstitué entre les mains de Jehan de Beauvoir puis de Jehan Malon (il hérita de ses parents et, à la suite d'accords successoraux, de son beau-père la moitié des biens acquis par Beauvoir et Agnès, très certainement les moulins et la justice).

89. Boutruche, Robert, La crise d'une société. Seigneurs et paysans en Bordelais pendant la guerre de Cent ans, Paris, 1947, p. 285; BouTRUCHE, Robert, " Aux origines d'une crise nobiliaire : donations pieuses et pratiques successorales en Bordelais du XIII ${ }^{\mathrm{e}}$ au XVI ${ }^{\mathrm{e}}$ siècle ", Annales d'histoire sociale, t. 1, 1939, p. 161-177 et 257-277.

90. WolfF, Philippe, "Une famille du XIII ${ }^{\mathrm{e}}$ au XVI ${ }^{\mathrm{e}}$ siècle, les Ysalguier de Toulouse ", Mélanges d'histoire sociale, t. 1, Paris, 1942, p. 52.

91. Barthelemy, Dominique, La société dans le comté de Vendôme..., op. cit., p. 863. L'auteur songeait d'ailleurs " à la contagion des usages roturiers ". 
pour conclure sur la situation en 1419 peut paraître dangereux : en effet, les tenures en parage n'étaient pas mentionnées et l'on peut se demander si les «feudataires multiples" l'étaient avec beaucoup de soin ${ }^{92}$. En outre, il ne faudrait pas oublier de noter que certaines terres démembrées retrouvèrent leur unité passée. Le fief formé par les métairies de Villetubœuf et la Ratellerie [Villiersfaux] avait été divisé (la veuve de Bouchard de SaintAmand avouant la première, Robin de Trénelles la seconde) : or, en 1419, il semblait avoir été reconstitué au profit de l'écuyer Guillaume de SaintAmand $^{93}$. Nous pourrions dire la même chose de Villetrun ou de l'ensemble formé par les moulins de la Chape et Chanteloup. Si nous sommes convaincu que les règles successorales sont essentielles pour comprendre les pratiques lignagères ou matrimoniales des Vendômois (nobles ou non), elles ne semblent pas fournir, d'après le Livre, d'explication à une éventuelle crise nobiliaire. En fait, d'une manière générale, elles étaient relativement propices à l'aînesse. Un procès de 1426 nous apprend que les parents ne pouvaient disposer que du tiers de leurs héritages, le reste devant aller à l'aîné ${ }^{94}$. La coutume était donc favorable au maintien de la propriété noble, plus qu'ailleurs, en Blésois ou en Poitou par exemple ${ }^{95}$.

\section{Un patrimoine chevaleresque liquidé?}

En Vendômois comme ailleurs, les chevaliers vendirent ${ }^{96}$. Toutefois, une logique patrimoniale suffit souvent à expliquer une mention de vente qui ne signifie pas forcément la fin d'un lignage. Jehan de Beauvoir avait acquis une partie de Villetrun en 1373. L'acte nous apprend que la vente comprenait " tous les arréages dus du temps passé à cause des rentes " (non autrement détaillées) ${ }^{97}$. Voilà qui pourrait alimenter notre " crise seigneuriale " et faire de Huet le Jay et sa femme Jehanne de la Boissière des nobles sur-endettés, incapables de régler leurs dettes. Toutefois, les Le Jay n'étaient pas de petits hobereaux locaux : Pierre le Jay était chevalier et seigneur de Fleurigny en 1276 . Son petit-fils était conseiller et chambellan du roi en 1379 et premier chambellan du duc d'Orléans. Il avait épousé Catherine Drouais, nièce de Jehan de Vendôme, seigneur de la Ferté $^{98}$. Nous pensons que Huet se débarrassa du patrimoine hérité de sa femme, parce que ses priorités étaient probablement ailleurs (et notam-

92. On trouve uniquement trois fiefs " partagés " au XVe siècle qui appartenaient à des roturiers ou des familles récemment anoblies (Livre des fiefs $\mathrm{n}^{\circ} 16,26,58$ ).

93. Livre des fiefs $\mathrm{n}^{\circ} 29$.

94. Arch. dép. du Loir-et-Cher, G 308, 1426.

95. GUERIN, Isabelle, La vie rurale en Sologne aux XIV-eXVe siècles, Paris, 1960, p. 173; FAVREAU, Robert, La ville de Poitiers..., op. cit., p. 525.

96. La veuve de Fouquet Poinvillain cédait à plusieurs reprises des " domaines " aux chanoines : cinq mouées de terres et prés, des cens et sa basse justice à Périgny; 30 sous de cens, six quartiers de pré et une rente en blé à proximité de Vendôme (Rocé, Naveil...); sa justice de 60 sous à Rocé.

97. Arch. dép. du Loir-et-Cher, E 192, 1373.

98. LA ChENAYE DES BoIs, op. cit. 
ment en Sologne et en Blésois $\left.{ }^{99}\right)$. Finalement, tout le monde trouvait son compte dans cette transaction : Beauvoir "le rassembleur de fief ", et le Jay qui cédait une terre héritée avec les arrérages de quelques rentes. La même utilisation des biens dotaux se retrouve chez l'écuyer Jehan du Plessis qui, lorsqu'il vendit à Les Perles [Vendôme] en 1364, cédait un fief qu'il tenait de sa femme, Jehanne de Lespine ${ }^{100}$. La remarque serait valable pour la métairie de Maurepas délaissée par le même en $1341^{101}$, ou pour celle de Pinoche [Crucheray] ${ }^{102}$. Dans tous les cas, il se débarrassait d'une partie d'un patrimoine hérité, pour ne garder que quelques fiefs, centrés autour de Berthault [Lancé] ${ }^{103}$ et Périgny/Selommes ${ }^{104}$. Pour des Plessis qui ne possédaient que la Chaise [Authon] ${ }^{105}$ et un habergement à Chaillou [commune de Boisseau, canton de Marchenoir] ${ }^{106}$, la promotion par le mariage était belle, avec la constitution d'une seigneurie "bicéphale ", en pleine Beauce vendômoise. Une rapide consultation du dictionnaire de Saint-Venant nous apprend que Villarceau et Berthault restèrent aux mains de la famille jusqu'à la fin du $\mathrm{XVI}^{\mathrm{e}}$ siècle, Périgny jusqu'au XVIII ${ }^{\mathrm{e}}$ siècle. La Chaise fut vendue en 1449.

Un dernier exemple nous permettra d'insister sur l'importance des "frontières féodales " dont les fluctuations ont pu favoriser certains reclassements. Dominique Barthélemy voyait dans la vente de la Béginière [Rocé] un exemple de naufrage nobiliaire ${ }^{107}$. S'il est indéniable que le vendeur, Jehan Vigoureux, était écuyer et l'acheteur bourgeois de Vendôme, le premier tenait probablement son habergement à la suite d'un partage successoral récent et peut-être contesté ${ }^{108}$. L'acte spécifiait qu'étaient cédées " toutes les choses que les demandeurs peuvent demander " (cette " demande "

99. Jehan le Jay était seigneur de Candé en Sologne (Arch. dép. du Loir-et-Cher, 3 H 103 , 1381). Guillaume (Huet?) le Jay était seigneur des Forges en 1355 (Arch. dép. du Loir-etCher, 3 H 110, 1355) : nous serions plus enclins à lire "Lorges " en Beauce, FALLOT, J., Patrimoine..., op. cit.

100. Bibli. mun. de Vendôme, ms. 285, 1364. Le fief des Perles avait été acquis par le bourgeois Pierre de Lespine en 1333, BARTHElEmy, Dominique, La société dans le comté de Vendôme..., op. cit., p. 995.

101. Bibli. mun. de Vendôme, ms. 285, 1341.

102. Arch. dép. du Loir-et-Cher, 21 H 72, 1367. La métairie de Pinoches appartenait à un oncle maternel.

103. Livre des fiefs $n^{\circ} 65$ : Les deux métairies de Berthault étaient héritées : l'une était à Pierre de Lespine, l'autre à «Guillaume de Jupeaux qui la tenoit de Bonin, qui en a fait son domaine par achapt".

104. La métairie de Villarceau [paroisse de Périgny, commune de Selommes] avouée par Jehan Bonin à cause de sa femme, Gilles de Lespine, en 1355. Des domaines en Périgny (le "Fie Troussier ") dénombrés par le même, Livre des fiefs n ${ }^{\circ} 64$ et 65 .

105. Saint-Venant, Raoul Barré de, Dictionnaire..., op. cit., I, p. 272.

106. " Item ce que Jehan fils de feu M. Guillaume du Plessis a au Chaillou, vallant seize livres de rente, c'est à savoir la moitié d'un hébergement, quatre mouées et quatre septrées de terre a la mesure de Marchenoir, au fief du seigneur de Chanteloup, rerefief du comté de Vendôme, et a présent du comté de Blois ", SulluIot, art. cit., p. 32.

107. Barthelemy, Dominique, La société dans le comté de Vendôme..., op. cit., p. 986-987 108. Il le tenait même peut-être de sa femme. Voilà qui expliquerait sa présence (et celle de son père) dans l'acte de vente. 
semble faire allusion à un procès en cours). De plus, "si les acheteurs sont molestés en justice à cause de la dicte vente, les vendeurs ont promis leur ouster à leurs propres cousts et despens tout l'empesthement ou encombrement qui mis y avoit esté109 ». Voilà qui traduisait certainement une situation difficile. D'autre part Vigoureux était châtelain de Blois ${ }^{110}$ alors même que Rocé, à la suite du bornage entre les comtés de Vendôme et Blois, avait rejoint la mouvance du premier ${ }^{111}$. Dominique Barthélemy avait évoqué le début d'une sorte de " rationalisation " qui conduisait à tracer des frontières moins floues entre châtellenies ${ }^{112}$. Peut-on faire l'hypothèse, en élargissant le concept, d'une conduite qui aurait consisté, pour les lignages blésois, à abandonner leurs fiefs " jadis blésois et à présent vendômois ${ }^{113}$ "? Constatons simplement, avant d'entreprendre des recherches plus approfondies, que la zone récupérée par Bouchard VI fut un terrain de prédilection des " conquêtes bourgeoises" (Rocé, Villemarais, Villeclèche, Faye, Villeromain...).

\section{Vers une relecture des " mésalliances "}

Si ces derniers paragraphes montrent que la gestion du patrimoine semble donc avoir été au centre des pratiques matrimoniales, ils permettent également de poser le problème de la "mésalliance ". Ce concept a surtout été développé par les juristes modernistes, à une époque où la noblesse était définie strictement et son renouvellement contrôlé : appliqué à un mariage entre deux membres issus de " groupes sociaux " différents (aristocratie et bourgeoisie), il était considéré comme infamant. Les historiens ont très largement repris ce concept en le modernisant et en en faisant un élément de la crise nobiliaire ${ }^{114}$. Certes, dans un premier temps, l'alliance entre une Jehanne de Lespine et un Jehan du Plessis ${ }^{115}$ avait de quoi surprendre. Toutefois, derrière le problème des " titres " et du statut social se cachait celui des terres et des seigneuries (sûrement plus important) : nous dirions hypergamie féminine pour le statut mais hypogamie pour les terres. Le mariage entre les Saint-Martin et les Beauxoncles offre un autre exemple d'union entre un ancien lignage nobiliaire et une famille de la nota-

109. Arch. dép. du Loir-et-Cher, G 287, 1366.

110. Clement, Pierre, Essai sur la famille des du Plessis, notes manuscrites conservées à la Société archéologique du Vendômois. La transaction est également conservée aux Arch. dép. du Loir-et-Cher, G 96, 1400 : Vigoureux semble être seigneur de Fossé près de Blois.

111. Barthelemy, Dominique, La société dans le comté de Vendôme..., op. cit., p. 835.

112. Ibidem, p. 830.

113. Une rapide consultation des archives blésoises (abbayes de Bourgmoyen, de SaintLomer...) pourrait nous renseigner sur le devenir des "fiefs jadis vendômois ": Landes, Villeruche, Champigny...

114. La lecture attentive de Michel Nassiet nous a appris à relativiser le concept de «mésalliance ", tant la pratique de l'hypogamie féminine était répandue au Moyen Âge, NASSIET, Michel, op. cit., p. 16.

115. Une famille de la vieille chevalerie vendômoise BARTHELEMY, Dominique, La société dans le comté de Vendôme..., op. cit., p. 957. 
bilité urbaine. Si les premiers avaient vendu quelques biens ou rentes au cours du XIV ${ }^{\mathrm{e}}$ siècle, rien ne nous permet de dire qu'ils étaient dans une situation critique ${ }^{116}$. Et pourtant, entre 1355 et 1419, ils perdirent deux seigneuries importantes : Maugué (dont l'aveu de 1377 nous révèle la richesse ${ }^{117}$ ) au profit des Malon et Faye au profit des Beauxoncles. Dominique Barthélemy, déjà, relativisait le "naufrage " en notant que ces "domaines " n'appartenaient pas d'ancienneté au lignage ${ }^{118}$. En outre, si Maugué fut probablement vendu, Faye partit entre les mains d'un gendre, Jehan Beauxoncles, bourgeois de Vendôme et possesseur de tanneries à Pezou $^{119}$. Sur les raisons de cette alliance très inégale (en fait un mariage hypogamique des filles), nous sommes réduit à émettre quelques hypothèses. Les possessions des Beauxoncles, dès avant leur mariage, étaient proches de celles des Saint-Martin. En 1387, Jehan et sa femme prenaient à rente de la Maison-Dieu la moitié d'une métairie à la Vacherie (Crucheray) et la moitié d'une autre métairie à Faye (tenues toutes deux à " foy et homage ") : ces héritages avaient été légués aux frères par Péronnelle veuve de Macé Copelet, un autre notable urbain ${ }^{120}$. La proximité géographique de ces biens et des possessions des Saint-Martin (Faye, Champgast en Crucheray ${ }^{121}$ ) n'est probablement pas fortuite : en effet, Macé était le fils et héritier de Jehan Copelet, qui figure parmi les acquéreurs potentiels de Maugué $^{122}$. Le mariage permit donc de reconstituer, entre les mains d'un gendre, de belles seigneuries qui avaient été touchées par un début de démembrement. Les Beauxoncles gagnaient en honneur et en terres. Les Saint-Martin mettaient fin à un processus qui aurait pu les mener à la ruine et facilitaient la perpétuation du lignage (certes à travers un gendre : mais cela posait-il tellement de problèmes?) dans de bonnes conditions maté-

116. En 1337, Jehan de Saint-Martin vendait une taille de 26 sous aux chanoines sur des terres à Périgny (Arch. dép. du Loir-et-Cher, G 2576, 1337). Son fils Jehan cédait une rente assise sur une métairie à Naveil, appartenant à la collégiale, pour 20 écus (Arch. dép. du Loir-et-Cher, G 279, 1359). Il amortissait des terres à la même contre 105 sous (Arch. dép. du Loir-et-Cher, G 267, 1352). Enfin, Pierre de Saint-Martin avait vendu à Regnault de Graçay une rente de 50 sous (Arch. dép. du Loir-et-Cher, 21 H 21, 1372).

117. AN, P 618, 1377 : habergement, dix mouées de terre, cens, basse justice, mouvance féodale (comprenant d'authentiques écuyers)...

118. Barthelemy, Dominique, La société dans le comté de Vendôme..., op. cit., p. 958.

119. Saint-Venant, Raoul Barré de, Dictionnaire..., op. cit., III, p. 44.

120. Bibli. mun. de Vendôme, ms. 285, 1387.

121. " En 1437 et en 1449, Champgast était à Jean Beauxoncles, héritier par représentation de sa mère, de feu Guillaume de Saint-Martin ", Saint-Venant, Raoul Barré de, Dictionnaire..., op. cit., I, p. 280.

122. Livre des fiefs $n^{\circ} 33$. Nous pensons que Guillaume de Saint-Martin vendit Maugué à Jehan Copelet qui redonna ensuite la seigneurie en dot à sa fille Agnès, avant qu'elle ne passe à son fils Jehan Malon, puis sa petite-fille Agnès (épouse de Bertrand Daguier, le feudataire de 1419). Trois éléments corroborent cette hypothèse : d'une part, le statut de Maugué semble avoir été celui d'une terre dotale (elle fut donnée en dot à Agnès Malon comme elle l'avait été à sa grand-mère). D'autre part, Macé Copelet, fils de Jehan, hérita de certains biens des Saint-Martin. Enfin, dans l'acte partageant les biens de feu Gervais Malon, aucune mention n'est faite à Maugué (Bibli. mun. de Vendôme, ms. 285, 1364). Il n'en fut donc probablement pas l'acquéreur. 
rielles. À la suite de ces mariages, les actes titrèrent plus facilement les roturiers hypergames (ou leurs enfants). Alors que Jehan Beauxoncles était bourgeois de Vendôme, son fils et seul héritier Jacques était chevalier en $1425^{123}$. Son petit-fils épousa à nouveau une certaine Catherine de SaintMartin (par la pratique des mariages doubles ${ }^{124}$ ), fille de Guillaume SaintMartin qui était seigneur de la Salle de Vieux-Pont (Vendôme) en 1409125, confortant ainsi le passage du patrimoine d'un lignage à l'autre. Si Jehan de Lespine ne semble pas avoir porté de titre après son mariage avec Isabelle (du Plessis?), son fils Pierre avait la chevalerie au soir de sa vie ${ }^{126}$. Jacques Louet, fils du bourgeois Jacquelin Louet et de Gilette Boisraoul, était écuyer en 1414, chevalier en $1427^{127}$, après avoir épousé Jehanne de Montigny ${ }^{128}$, issue de l'illustre lignage dont Dominique Barthélemy a souligné l'ancienneté et le prestige (ils étaient lointains cousins des comtes de Vendôme, prédécesseurs des Bourbon) ${ }^{129}$.

\section{Anoblissement et noblesse}

Ces dernières lignes nous montrent combien il est nécessaire de différencier l'anoblissement de la "reconnaissance sociale " de la noblesse. Philippe Contamine a écrit que « le prince pouvait évidemment créer des ancêtres à celui qu'il voulait récompenser : il lui était loisible de le faire

123. Arch. dép. du Loir-et-Cher, G 239, 1425.

124. Ces " doubles mariages " permirent souvent la constitution de "pôles " puissants autour de quelques familles. "Souvent on préférait chercher un conjoint dans l'entourage déjà connu, c'est-à-dire le voisinage et/ou la parenté " en raison notamment du fait que l'interconnaissance permettait une plus grande confiance ", NASSIET, Michel, ouvr. cit., p. 155. Elle concerna les comtes de Vendôme : le 28 septembre 1364, Catherine de Vendôme (fille de Jehan VI) épousait Jehan de Bourbon, le fils du comte de la Marche. Or le même jour, la fille de ce dernier épousait l'aîné de Jehan VI, le tout nouveau comte Bouchard VII. Nous faisons l'hypothèse d'un même type d'alliance pour Isabelle et Jehan du Plessis, mariés avec Jehan et Jehanne de Lespine. Enfin, les mêmes lignages s'unirent à des générations différentes, créant ainsi un cycle de l'échange : ce fut le cas des Beauxoncles et des Saint-Martin. Ces mariages restreints manifestaient bien la volonté forte d'unir deux familles : leurs motivations furent très souvent économiques ou foncières. En effet, si les Vendôme gagnaient en prestige grâce à cette alliance (la fille de comte épousait un descendant de saint Louis), les Bourbon renforçaient peut-être leur présence dans la partie méridionale du royaume (avec la seigneurie de Castres). C'est un " accident " démographique qui leur apporta, par la suite, le comté. Le second mariage entre Saint-Martin et Beauxoncles acheva le passage du patrimoine des premiers aux seconds. Si nous n'avons pas réussi à expliquer les échanges matrimoniaux entre Copelet/Malon et Plessis/Lespine, le problème des terres semble avoir été déterminant. 125. Saint-Venant, Raoul Barré de, Dictionnaire..., op. cit., III, p. 347.

126. Feu Messire Pierre de Lespine, chevalier, "demourrant à Vandosme ou es environs " avait légué aux chanoines de Saint-Georges une rente de quatre muids froment (Arch. dép. du Loir-et-Cher, G 250, 1453).

127. Arch. dép. du Loir-et-Cher, G 245, 1414; 21 H 40, 1427.

128. " Après le trespas de feue Jehanne Louette, fille et seule héritière de feu messire Jacquet Louet en son vivant chevalier et de dame Jehanne de Montigny sa femme ", AN, Q 1439, 1438.

129. Barthelemy, Dominique, La société dans le comté de Vendôme..., op. cit., p. 959. 
noble mais non point gentilhomme ${ }^{130}$ ". Jehan de Lespine, qui fut anobli par le roi en 1355, vérifie l'affirmation ${ }^{131}$. Nous ne connaissons pas les motifs de cette faveur, mais il faut constater que son beau-père, Hugues Bonin, était très proche des hautes sphères de l'État : qualifié de chevalier du roi, il était également maître d'Hôtel de la reine mère ${ }^{132}$. Toutefois, malgré cet honneur royal, Jehan de Lespine ne fut pas titré. Son fils Pierre (dont la mère était peut-être Isabelle du Plessis) était écuyer en 1385, alors qu'il avouait au comte de Vendôme sa justice de Meslay ${ }^{133}$. À partir de cette date, les Lespine portèrent presque toujours l'armigérat et très rapidement la chevalerie $^{134}$. Quel intérêt Jehan avait-il à se faire anoblir par le roi? Nous pensons que la dispense de franc-fief pouvait attirer un tel rassembleur de seigneuries ${ }^{135}$. Les Malon pourraient eux-mêmes vérifier l'hypothèse $a$ contrario. En effet, alors qu'ils semblaient très proches des Lespine en termes de notabilité et de richesse, ils n'accédèrent pas aux titres nobiliaires avant la seconde moitié du $\mathrm{Xv}^{\mathrm{e}}$ siècle. Nous supposons la dispense moins utile alors qu'ils semblent davantage avoir été des héritiers (déjà) que de véritables " conquérants ${ }^{136}$ ". Deux stratégies familiales sont perceptibles ici : l'acquisition de seigneuries, l'anoblissement royal, les mariages avec la prestigieuse aristocratie locale d'une part; l'héritage, la pratique et les offices (royaux notamment) de l'autre.

Après « le demi-siècle le plus dur ${ }^{137}$ ", le calme semble être revenu dans le Vendômois médiéval. Le monde des feudataires ne subit pas de modifications importantes entre 1355 et 1419 . Certes, des fiefs changèrent de mains mais souvent en fonction de politiques matrimoniales et patrimoniales complexes et qui nous échappent encore trop souvent. Enfin le service du Prince (qu'il soit d'Angers, de Blois ou de France) enleva plusieurs familles au comté dont l'ouverture sur le reste du royaume grandit avec

130. ConTAmine, Philippe, op. cit., p. 20.

131. "Johannes de Spina de Vindocino nobilitatur an. 1355 " (Registre des anoblissements royaux, AN, JJ 98, ch. 115).

132. Peut-on faire l'hypothèse, pour Hugues Bonin, d'un anoblissement ob servitia domestica? Nous en doutons car Jehan Bonin, son frère ou son père, était également écuyer d'après le Livre. Les informations concernant Hugues Bonin proviennent en partie de son sceau ( $\left.{ }^{\circ} 1216\right)$, Inventaire de la collection Clairambault à la Bibliothèque nationale, Demay Germain, Paris, 1885-1886.

133. AN, P 621, 1385.

134. Pierre lui-même fut chevalier : un acte de 1453 nous apprend qu'il avait été chevalier de son vivant (et qu'il avait donné une rente de 4 muids froment aux chanoines de Saint-Georges), Arch. dép. du Loir-et-Cher, G 250, 1453.

135. Barthelemy, Dominique, La société dans le comté de Vendôme..., op. cit., p. 992 et suivantes.

136. Héritiers des Copelet pour les terres et prés à Areines (Livre des fiefs $n^{\circ} 13$ ); pour la justice de Poiriers (Livre des fiefs $\left.n^{\circ} 15\right)$; pour Maugué (Livre des fiefs $n^{\circ} 33$ ). Mais également héritiers des Beauvoir (Moulins de la Chape, $n^{\circ} 20$ ). Gervais Malon acquit surtout des rentes (62 livres, un muid froment sur Guillaume de Poncé) et métairies (deux métairies à Naveil en 1351 et 1352), Bibli. mun. de Vendôme, ms. 285, 1362.

137. Barthelemy, Dominique, La société dans le comté de Vendôme..., op. cit., p. 955. 
l'arrivée des Bourbon. Après avoir montré, tout au long de ce travail, que des mentions éparses de vente ou une disparition du corpus ne permettaient pas de mettre en évidence les difficultés d'un lignage, nous nous interdirons de parler d'une éventuelle « crise nobiliaire ${ }^{138}$ ". Plusieurs lignages maintinrent leurs positions. Si la richesse des Trôo s'étalait avec insolence dans le Livre des fiefs de 1355, les mentions de 1419 prouvent un dynamisme qui ne faiblit pas. L'alliance prestigieuse avec Pierre d'Arquenay, chevalier et chambellan de Louis d'Anjou ${ }^{139}$, prouvait d'ailleurs leur importance ${ }^{140}$. Certes, la période vit le renforcement de quelques fortunes « bourgeoises " : celles des Lespine, mais également des Malon, Louet, Moreau, Beauxoncles et Bégin. Toutefois, deux remarques sont nécessaires. D'une part c'est bien dans la première moitié du XIV ${ }^{\mathrm{e}}$ siècle qu'il faudrait véritablement placer le take-off de l'ascension (pour les Lespine et Copelet notamment). Les Louet, Beauxoncles et Malon ne faisaient-ils pas déjà figure d'héritiers, se contentant d'arrondir des domaines échus par mariage? D'autre part, si le Livre marque bien une certaine continuité familiale entre 1355 et 1419, il masque les changements de statut. Qu'ont de commun Jehan de Lespine et son fils ou petit-fils Pierre, tous deux non titrés dans notre document? Si l'un fut seulement " de Vendôme ", l'autre mourut chevalier renouvelant ainsi l'aristocratie sans révolutionner la société médiévale.

Nous ne terminerons pas sur ce bourgeois, dépeint naguères comme profitant de la première occasion pour s'intégrer à la noblesse et ainsi trahir sa classe. Si l'anoblissement "social " (c'est-à-dire reconnu par la société) reposa sur la possession de seigneuries, les mariages illustres et peut-être la résidence rurale ${ }^{141}$, il fut avant tout dicté par un mélange subtil de nécessité et de volonté. Un choix que ne semblent pas avoir fait les Malon, davantage tournés vers le service du Prince : du tabellionage de Vendôme au Parlement de Paris, les offices permirent ou couronnèrent une ascension dont nous ne saurions dire que la noblesse fut le moteur essentiel ou le point d'orgue.

138. Comment appréhender un tel phénomène alors que nous ne possédons pas de comptabilités ou de chartriers seigneuriaux? Une étude statistique précise est impossible. Nous pouvons simplement constater que la Collégiale profita des ventes bourgeoises ou nobiliaires sans aucune distinction.

139. Livre des fiefs $n^{\circ} 34$

140. Ce maintien des anciens lignages avait été mis en valeur par R. Boutruche pour qui " le noble, c'est-à-dire le guerrier, le pensionner, avait parfois sauvé le seigneur ". Guy Fourquin s'interrogeait légitimement quant au devenir de familles dont la survie reposait sur les profits de guerre.

141. Pierre de Lespine demeurait à " Vendôme ou ès environs " (Arch. dép. du Loir-etCher, G 250, 1453). Jacquelain Louet vivait à la Thibauldière près de Naveil (Arch. dép. du Loir-et-Cher, G 245, 1414), tout comme les Ysalguier qui se tournaient de plus en plus vers la campagne et recherchaient les mariages avec la noblesse terrienne : WoLfF, Philippe, "Une famille du XIII ${ }^{\mathrm{e}}$ au XVI ${ }^{\mathrm{e}}$ siècle, les Ysalguier de Toulouse ", Mélanges d'histoire sociale, t. 1, Paris, 1942, p. 25-58, voir p. 43. 
Annexe 1 - Les relations entre les feudataires de 1355 et ceux de $1419^{142}$

\begin{tabular}{|c|c|c|}
\hline Livre des fiefs $\mathrm{n}^{\circ}$ & lien certain & lien possible \\
\hline 1 & Gendre & \\
\hline 2 & Gendre & \\
\hline 3 & & Fils \\
\hline 4 & & Gendre \\
\hline 5 & & Liens familiaux probables \\
\hline 6,12 & Achat & \\
\hline $7,70,71,72$ & & Liens familiaux probables \\
\hline 8 & & $?$ \\
\hline 9 & & $?$ \\
\hline 10 & & Gendre \\
\hline $11,56,73$ & Gendre & \\
\hline 13 & Fils & \\
\hline 14 & & Liens familiaux probables \\
\hline 15 & & $?$ \\
\hline 16 & & Fils - Gendre \\
\hline 17 & & Liens familiaux : cousin? \\
\hline 18 & Achat & \\
\hline 19 & & Fils \\
\hline 20 & Achat & \\
\hline 21 & Le même (d'après le Livre) & Plus certainement un Fils \\
\hline 22 & & Liens familiaux probables \\
\hline 23 & Don ou achat & \\
\hline 24 & & $?$ \\
\hline 25 & Neveu par alliance & \\
\hline 26,43 & Arrière-petit-fils & \\
\hline 27 & & Alliance matrimoniale \\
\hline 28 & & $?$ \\
\hline 29 & & $?$ \\
\hline 30 & Neveu & \\
\hline 31 & Achat & \\
\hline 32 & & Liens familiaux probables \\
\hline 33 & & Achat \\
\hline $34,59,69$ & & Liens familiaux \\
\hline 35 & Achat & \\
\hline 36 & & $?$ \\
\hline 37 & & Achat ou don puis bail à rente \\
\hline 38 & & T \\
\hline 39 & & Fils ou petit-fils \\
\hline 40 & & Fille \\
\hline 41 & Achat ou don & \\
\hline 42 & & Fils \\
\hline
\end{tabular}

142. Ces reconstitutions ont été rendues possibles par le dépouillement des archives conservées aux archives départementales du Loir-et-Cher ou à la bibliothèque municipale de Vendôme. Elles feront prochainement l'objet d'un article dans le bulletin de la Société archéologique du Vendômois. 


\begin{tabular}{|c|c|c|}
\hline 44 & & Achat ou vente \\
\hline 46 & Don ou achat & \\
\hline $45,52,53,61$ & & Frère \\
\hline 47 & & $?$ \\
\hline 48 & & $?$ \\
\hline 49 & & Gendre \\
\hline 50 & Achat & \\
\hline 51 & & Achat puis " don" \\
\hline 54 & Fils & \\
\hline 55 & & Fils ou petit-fils \\
\hline 57 & Achat & \\
\hline 58 & Achat & \\
\hline 60 & Achat & \\
\hline 62 & & Fils ou petit-fils \\
\hline 63,77 & & Fils ou petit-fils \\
\hline $64,65,78$ & & Liens familiaux \\
\hline 66 & & Liens familiaux (gendre?) \\
\hline 67 & Achat puis héritage & \\
\hline 68 & & $\begin{array}{c}\text { Achat ou " défaut d'homme" } \\
\text { puis bail }\end{array}$ \\
\hline 73 & & \\
\hline 74 & Don & \\
\hline 75 & & Liens familiaux probables \\
\hline 76 & & Fils \\
\hline 79 & Fils & \\
\hline 80,81 & & Femme \\
\hline
\end{tabular}

\section{Bibliographie}

(Cette bibliographie ne se veut pas exhaustive)

Bors, Guy, Crise du féodalisme. Économie rurale et démographie en Normandie du début du XIve au milieu du XVIe siècle, Paris, 1976.

BouTRuche, Robert, La crise d'une société. Seigneurs et paysans en Bordelais pendant la guerre de Cent Ans, Paris, 1947.

CARON, Marie-Thérèse, La noblesse dans le duché de Bourgogne (1315-1477), Lille, 1987.

ChARBOnNIER, Pierre, Une autre France. La seigneurie rurale en Basse-Auvergne, Clermont-Ferrand, 1973.

CHARBOnNIER, Pierre, Guillaume de Murol. Un petit seigneur auvergnat au début du Xve siècle, Clermont-Ferrand, 1973.

CHEVALIER, Bernard, La ville de Tours et la société tourangelle (1356-1520), 2 vol., Thèse de doctorat d'État, Université de Lille III, 1974.

Contamine, Philippe, Guerre, État et société à la fin du Moyen Âge. Études sur les armées des rois de France (1337-1494), Paris, 1972.

Contamine, Philippe, La noblesse au Moyen Âge, Paris 1976.

GuEnEE, Bernard, Tribunaux et gens de justice dans le bailliage de Senlis à la fin du Moyen Âge (vers 1380-vers 1550), Paris, 1963. 
FouRQuin, Guy, Les campagnes de la région parisienne à la fin du Moyen Âge, Paris, 1964.

LEGUAY, André, De la seigneurie à l'État. Le Bourbonnais pendant la guerre de Cent Ans, Moulins, 1969.

LE MENE, Michel, Les campagnes angevines à la fin du Moyen-Âge (1350-1539), Nantes, 1982.

Les Élites urbaines au Moyen Âge, 27e Congrès de la Société des Historiens médiévistes de l'Enseignement supérieur, Rome-Paris, mai 1996, Publications de la Sorbonne, Paris, 1997.

LORCIN, Marie-Thérèse, Les campagnes de la région lyonnaise aux XIVe et XVe siècles, Lyon, 1974.

Matteoni, Olivier, Servir le Prince. Les officiels des ducs de Bourbon à la fin du Moyen Âge (1356-1523), Publications de la Sorbonne, Paris, 1998.

Morsel, Joseph, "Pour une étude du pouvoir de la noblesse à la fin du Moyen Âge ", Bulletin d'information de la mission historique française en Allemagne, $\mathrm{n}^{\circ} 11,1985$.

PHALIP, Bruno, Le château et l'habitat seigneurial en Haute Auvergne et Brivadois entre le XI et le $X V^{e}$ siècle, Thèse d'histoire, Université de Paris IV, 1990.

PERROY, Édouard, "Social mobility among the French Noblesse in the latter middle ages ", Past and Present, 1962, p. 25-38.

SCHNEIDER, Jean, La ville de Metz aux XII⿸'-XIVe siècles, Nancy, 1950.

TRICARD, Jean, Les campagnes limousines du XIVe au XVe siècle : originalité et limites d'une reconstruction rurale, 3 vol., Thèse d'État, Université de Paris I, 1994. 


\section{RESUME}

Le Livre des Fiefs, qui fournit pour la période 1355-1419 la liste des vassaux du comte de Vendôme, permet de nuancer les impressions qui se dégagent de nombreuses études historiques centrées sur la " crise nobiliaire " du bas Moyen Âge occidental. S'il éclaire un dynamisme comtal qui se traduisit souvent par une politique d'acquisition de fiefs au détriment de l'ancienne chevalerie, nous ne pouvons dire que celle-ci connut des difficultés importantes. En fait, il semble nécessaire de porter un regard nouveau sur les " preuves " du déclin chevaleresque. Ainsi, les ventes de seigneuries semblent plutôt témoigner de pratiques qui peuvent être expliquées par la circulation des biens dotaux ou le déplacement spatial de certaines lignées. C'est trop souvent de l'illogisme apparent de ces politiques patrimoniales que nous tirons l'argument du déclin. De même, le mariage entre bourgeoisie et chevalerie ne saurait être considéré systématiquement comme " mésalliance " : très souvent, il répond à une pratique répandue dans la société médiévale ('hypogamie des femmes) et à des enjeux patrimoniaux que nous devons nous attacher à découvrir. La " percée " bourgeoise, enfin, ne fut pas nette dans le Vendômois bas médiéval : si elle s'accompagna, parfois, d'une reconnaissance social de la noblesse, l'anoblissement ne fut pas toujours le moteur ou le point d'orgue d'un hypothétique cursus honorum du notable citadin. Il fut lié aux circonstances et aux nécessités pratiques ('exemption du franc-fief par exemple) commandées par une politique tournée vers l'acquisition de fiefs que nous appelons trop souvent seigneuries.

\section{ABSTRACT}

The Book of Fiefs that supplies, for the 1355-1419 period, the list of vassals of the earl of Vendôme, allows to qualify the feelings that emerges from many historical studies focused upon the "crise nobiliaire" of the western Late Middle-Ages. While it throws light on a count dynamism that often found expression in a policy of fiefs acquiring to the detriment of the ancient knighthood, we cannot say that this one went through important difficulties. In point of fact, it seems necessary to have a new point of view on the evidence of the knightly decline. Thus, the seigniories sales rather seem to attest practises that can be explained by circulation of dowry properties or space movement of some lineages. It is too often from obvious illogicality of these inheritance policies that we conclude on the decline. Likewise, marriage between burgesses and knighthood cannot be systematically considered as "misalliance", it corresponds very often to a widespread practice in the medieval society (women hypo gamy) and to inheritance stakes that we must force ourselves to find out. The bourgeois breakthrough, then, was not clean in the Vendôme late medieval : while it was sometimes accompanied with a social acknowledgement of nobility, ennoblement was not always the mover or the achievement of an hypothetical cursus honorum of the urban notable. It was closely linked to circumstances and practical necessities (exemption of the franc-fief for instance) ordered by a policy turned to fiefs acquiring that we too often call seigniories. 